\title{
Formation of new methodological approaches to determining the cost of equipment for capital construction projects
}

\author{
Olga Didkovskaya ${ }^{1}$, Alexey Bocharov ${ }^{1,}$, Olga A. Mamayeva ${ }^{1}$ \\ ${ }^{1}$ Samara State Technical University, Institute of Architecture and Civil Engineering, \\ 194, Molodogvardeyskaya St., 443001, Samara, Samara
}

\begin{abstract}
The article presents author's ideas on the transformation of methodological approaches to determining the cost of technological equipment associated with capital construction objects. Diagnostics showed that the estimated norms for the installation of equipment in the current estimate and regulatory database contain hundreds of obsolete items. At the same time monitoring of the equipment market and comparison of its result with the norms show the absence of even more positions necessary for calculating the cost of modern equipment for capital construction projects. The proposed changes in the existing practice of standardizing the costs of installing equipment using obsolete estimates are based on the results of the author's analysis. The analysis is carried out in the form of continuous diagnostics of existing standards and their comparison with modern market indicators and methods of determining the cost of technological equipment, its installation and commissioning. Authors propose to revise the methodological approaches to determining the estimated cost of industrial equipment, bringing it closer to the real market pricing conditions. The formation of current standards should be made on the basis of analysis and processing of information from manufacturers/suppliers and collective peer reviews, i.e. through analytical, statistical and expert methods.
\end{abstract}

\section{Introduction}

The task of determining the cost of technological equipment for capital construction projects is now classified as complex. Its complexity is due to several reasons. Technological equipment, on the one hand, is functionally connected with objects of capital construction and is a part of them, while on the other hand it has specific features. The life cycles of the capital construction object and equipment differ by several times. The dynamics of changes in the functional, technical and cost characteristics of equipment significantly outstrips similar indicators of construction products. In this connection, the normative approach applied in determining the cost of construction in terms of technological equipment does not give a reliable result [4].

\footnotetext{
${ }^{*}$ Corresponding author: kafedra cen@mail.ru
} 


\section{Materials and Methods}

\subsection{Budget-normative base as a basis for determining the cost of technological equipment}

According to the technological structure of capital investments, the cost of construction includes three basic elements (1):

$$
C_{\text {cons }}=C_{w}+C_{e q}+C_{o t h},
$$

$\begin{array}{ll}C_{c o n s} & \text { - cost of construction, roubles; } \\ C_{w} & \text { - cost of work, roubles; } \\ C_{e q} & \text { - cost of equipment, roubles; } \\ C_{\text {oth }} & \text { - other expenses, roubles. }\end{array}$

Equipment of capital construction projects is represented by two categories engineering and technological. Engineering equipment includes equipment that carries a functional load in a building or structure and provides specified parameters for the operation of a building or structure. Technological equipment is the equipment of an enterprise for which construction (reconstruction, overhaul) of capital construction facilities is being carried out, used in technological processes of processing, output of products (rendering services) [3].

The cost of engineering equipment (electrical equipment, sanitary fixtures, etc.) is included in the cost of the relevant work (installation of a power supply system, etc.).

In formula (1), the cost of equipment allocated to an independent component of the cost of construction refers to the cost of technological equipment of the capital construction object.

Currently, the formation of the cost of construction at the stage of preparation of project documentation is carried out using the estimate norms. The current state system of estimate norms includes more than 230 collections of elemental norms, unit prices, estimated prices for building resources, etc.

An estimate and regulatory framework is also used to determine the estimated cost of equipment (compilations of State itemized estimates - CSIEe-2001, and Federal unit rates for equipment installation - FURe-2001). The problem is that the estimate norms for installation of equipment have not been updated for more than 30 years and have long been inadequate for modern developments in the equipment market.

\subsection{Diagnostics and analysis of estimate norms for equipment installation}

Diagnostics of estimate norms for installation of equipment was carried out by the authors in the form of a continuous expert examination of the estimate norms contained in the collections of CSIEe-2001, in accordance with the procedure established for these purposes.

Analysis of information resources of manufacturing companies, suppliers, service companies was conducted to analyze information on the relevance of equipment included in the compilation of estimates (Table 1). 
Table 1. Primary diagnostics of estimate norms.

Number and title of the compilation of estimates (CSIEe-2001)
Groups of equipment presented in the collection
Number of enterprises in the industry that produce equipment

\begin{tabular}{llcc}
\hline \multicolumn{1}{c}{1} & \multicolumn{1}{c}{2} & 3 \\
\hline $\begin{array}{l}81-02-04-2001 \\
\begin{array}{l}\text { Crushing-grinding, concentrating and } \\
\text { agglomeration equipment }\end{array}\end{array}$ & $\begin{array}{l}\text { Crushing-grinding, and } \\
\text { agglomeration equipment }\end{array}$ & 65 \\
\hline $\begin{array}{l}81-03-07-2001 \\
\text { Compressor units, pumps and fans }\end{array}$ & $\begin{array}{l}\text { Compressor; compressor, injection and } \\
\text { refrigeration; ventilating; pumping }\end{array}$ & 30 \\
\hline $\begin{array}{l}81-02-09-2001 \\
\text { Electric furnaces }\end{array}$ & $\begin{array}{l}\text { Electric furnaces for heat treatment and drying of } \\
\text { industrial purposes; electric furnaces for steel- } \\
\text { making }\end{array}$ & 18 \\
\hline $\begin{array}{l}81-02-15-2001 \\
\text { Gas treating equipment }\end{array}$ & $\begin{array}{l}\text { Purification of gases by filtration; mechanical } \\
\text { cleaning of gases; electrical cleaning of gases }\end{array}$ & 14 \\
\hline $\begin{array}{l}81-03-18-2001 \\
\text { Equipment for chemical and } \\
\text { petrochemical industry }\end{array}$ & Chemical industry; petrochemical industry & 26 \\
\hline $\begin{array}{l}81-03-19-2001 \\
\text { Equipment for coal and peat industry }\end{array}$ & $\begin{array}{l}\text { Coal industry - mine equipment; for open mining; } \\
\text { peat industry }\end{array}$ & 7 \\
\hline $81-03-20-2001$ & & \\
\hline
\end{tabular}

81-03-20-2001

Alarm, centralization, interlocking and contact network equipment in

Alarms; centralization; blocking; contact network railway transport

81-03-23-2001

Equipment for electrical industry

Manufacture of cable products; electric machine building; electrical porcelain industry; production of electrical insulating materials; production of light sources

81-02-25-2001

Equipment for the pulp and paper industry

Preparation of wood raw materials for processing; production of cellulose and semi-cellulose; production of thermomechanical, waste paper and wood pulp; dissolution and grinding of fibrous materials; thickening; storage, mixing and transportation of the mass; cleaning of paper and cardboard mass; production of paper, cardboard, commodity pulp and commercial wood pulp; packing and transportation of paper, cardboard and cellulose; application of water-dispersed and film coatings to paper and cardboard; processing of paper and cardboard; preparation of liquors and chemical reagents; fiber collection and effluent treatment

81-02-27-2001 Forming equipment; printing equipment;

Equipment for printing industry bookbinding and binding equipment; equipment for manufacturing and finishing of cardboard and stationery

\begin{tabular}{|c|c|c|}
\hline $\begin{array}{l}81-02-29-2001 \\
\text { Equipment for theater and } \\
\text { entertainment industry }\end{array}$ & $\begin{array}{l}\text { Winches and drives; suspension equipment and } \\
\text { supports; ropes; stage floor equipment; fences }\end{array}$ & 6 \\
\hline $\begin{array}{l}81-02-31-2001 \\
\text { Equipment for cinema industry }\end{array}$ & Film technology; film copying; film laboratory & 6 \\
\hline $\begin{array}{l}81-03-32-2001 \\
\text { Equipment for electronics and } \\
\text { communication industry }\end{array}$ & $\begin{array}{l}\text { Equipment for electronics and communication } \\
\text { industry }\end{array}$ & 7 \\
\hline $\begin{array}{l}83-03-36-2001 \\
\text { Equipment for consumer services and } \\
\text { utilities }\end{array}$ & $\begin{array}{l}\text { Laundry; dry cleaning and dyeing; repair of } \\
\text { household appliances }\end{array}$ & 4 \\
\hline Total & & 268 \\
\hline
\end{tabular}




\section{Results}

\subsection{Main results of diagnostics and analysis of estimate norms for equipment installation}

Diagnostics of estimate norms was made according to the full nomenclature of estimate norms presented in the collections of CSIEe-2001 (2664 items) [2].

Graphical interpretation of the main diagnostic results is shown in Figures 1 and 2.

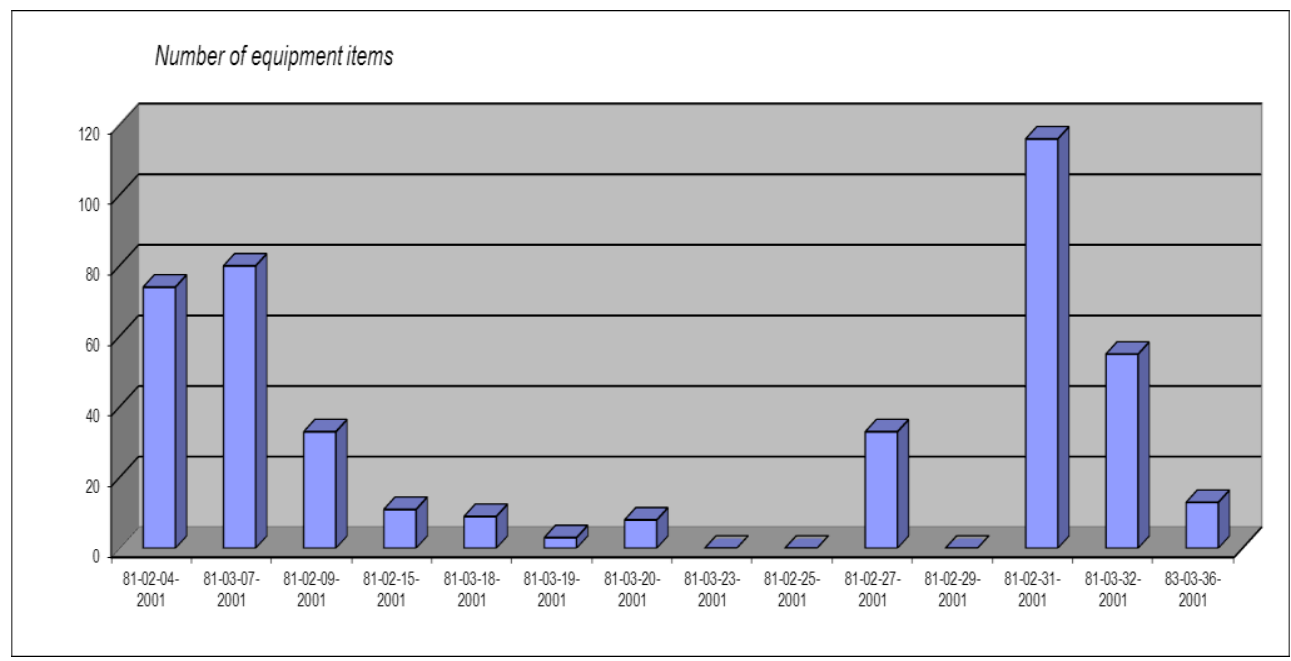

Fig. 1. Inactive items in State itemized estimates for equipment installation 2001, based on the diagnostic results in the context of analyzed collections.

Analysis of the current estimate norms for the installation of equipment showed that the collections of CSIEe-2001 contain 435 items of irrelevant equipment, which are present in the estimates but not produced by modern industry (Figure 1).

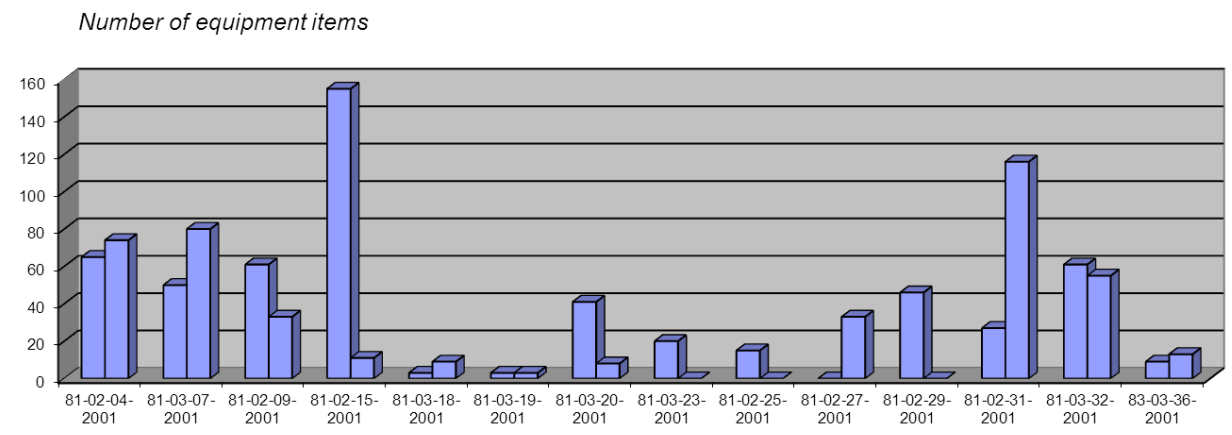

Fig. 2. Missing items in State itemized estimates for equipment installation 2001, based on the diagnostic results in the context of analyzed collections.

At the same time, the number of missing items of modern equipment, which is actually used at the capital construction facilities today, is more than 550 (Figure 2). 


\subsection{Features of the study subject, revealed as a result of diagnostics and analysis of estimate norms for installation of equipment}

As a result of the analysis of the collections for equipment installation the following features were revealed:

- the need to take into account the industry specificity of collections;

- the need for analysis of modern production and technological processes in various sectors of the economy;

- the need for a comparative analysis of technical and technological characteristics of equipment provided for by estimate norms and equipment used in modern production in the sectoral context;

- market research of technological equipment (in the context of a competitive market) and/or information from producers and suppliers in the sectoral context;

- study of current experience and established practice in terms of equipment installation technologies and cost formation.

The collections of State itemized estimates for equipment installation (CSIEe-2001) and Federal unit rates for equipment installation (FURe-2001) are conventionally classified into the following groups according to the nature of their use:

- estimate norms for the installation of general engineering equipment used to determine the estimated cost of various production and non-production facilities;

- estimate norms for the installation of general-purpose technological equipment used to determine the estimated cost of various production and non-production facilities;

- estimate norms for the installation of industry-specific technological equipment used to determine the estimated cost of highly specialized production facilities.

The proposed classification meets the objectives of further diagnostics and updating of methodological approaches to the formation of the estimated cost of equipment.

We propose to update the collections of CSIEe-2001assigned to the first $(8,10-12)$ and the second $(3,5-7,37-40)$ classification groups in the same general order as the compilation of estimates for construction and special construction work CSIE-2001.

We also propose to revise the methodological approaches to determining the estimated cost of industrial technological equipment (the third group - 1, 2, 4, 9, 13-36).

\subsection{Trends in the development of pricing in terms of determining the cost of equipment}

As a result of the analysis of modern industrial production processes, manufacturers and suppliers of technological equipment the following trends have emerged:

- CSIEe-2001 contains a huge amount of obsolete equipment that has not been produced (since the 1970s) and equipment that is not used at present. A small part of such equipment is replaced by its modernized versions (for example, in the collection of CSIEe 81-02-15-2001 "Gas treating equipment" only three items have modernized and used analogues from the entire range of estimate norms, the remaining items are completely outdated - mechanical and filtration cleaning is done today in other ways with the use of different equipment);

- many modern production and technological processes use equipment that is not listed in CSIEe-2001 (e.g., CSIEe 81-02-04-2001 "Crushing-grinding, concentrating and agglomeration equipment" Section 1 of Division 2 is represented by one type of equipment - disc screen, while in fact currently four types of such equipment are used: disc, inertial, self-balancing, and electric screens);

- for some industry-specific technological equipment there is a functioning competitive producer/supplier market, represented by domestic and import manufacturers (e.g., 
equipment of textile, printing, food processing, light industry, consumer services and municipal services, etc.); for other types of equipment manufacturers are represented by only a few enterprises (for example, equipment for cleaning gases, etc.);

- a significant share of specialized industrial equipment belongs to the individual delivery category;

- $\quad$ reduction in the mass of modern equipment similar/superior to outdated and unused one in performance and/or other characteristics, as a parameter that determines the cost of its installation;

- changes in the basic equipment parameters that determine the choice/selection of the estimate norm (e.g., "productivity" instead of "mass", etc.);

- a significant share of highly specialized industrial technological equipment is offered by manufacturers/suppliers "in business" (i.e. installed and adjusted);

- collection of information on cost indicators of industry-specific technological equipment. In response to requests, suppliers/producers generally propose to perform a cost estimate for the process parameters specified by the customer, taking into account the installation and commissioning "in the kit".

\section{Discussion}

\section{Proposals on the formation of actual methodological approaches to determining the cost of equipment for capital construction projects}

Formation of norms should be carried out on the basis of analysis and processing of information from producers/suppliers and collective peer reviews, i.e. analytical, statistical and expert methods.

Such approach to determining the estimated cost was established for laboratory equipment [5]: "The cost of installing laboratory equipment and furniture supplied assembled and not requiring preliminary disassembly and subsequent assembly during installation, as well as connection to engineering networks and communications (electricity, sewerage, gas supply, ventilation, etc.) are determined at a rate of $1 \%$ of their cost, taking into account the costs of unloading from vehicles, lifting to floors and bringing up to the installation site.

The costs for the installation of laboratory equipment and furniture supplied in disassembled form, or requiring disassembly and subsequent assembly for installation with connection to engineering networks and communications (electricity, water, gas, sewerage, ventilation, etc.) are determined in the amount of $6 \%$ of their cost, taking into account the costs of unloading from vehicles, lifting to floors and bringing up to the installation site.

The cost of the same works without connection to engineering networks and communications, is determined at a rate of $4 \%$ of the equipment cost."

Similar approaches are also used in appraisal practice with a view to reliable valuation of machinery and equipment $[1,6,7,8]$.

The proposed new approach to the formation of the cost of industry-specific technological equipment can be expressed through the following formula (2):

$$
C_{e q}^{e s t}=P_{e q} \times \frac{N_{c}}{100}
$$

$C_{e q}^{e s t} \quad$ - estimated cost of technological equipment, roubles; 

$P_{e q}$
- equipment purchase price, roubles;
$N_{c}$ equipment "in business" (installed and adjusted) to the purchase price of equipment, $\%$.
- comprehensive average norm that determines the ratio of the cost of

The purchase price of equipment $\left(P_{e q}\right)$ can be determined in the following way:

- by types of technological equipment for which there is a functioning competitive market, price indicators can be weighted averages determined on the basis of monitoring carried out in the order established for construction resources;

- by types of technological equipment of the so-called individual delivery price indicators can be determined by calculation in the order and forms established for this purpose.

The main normative and methodological task in establishing such an approach is the formation of complex norms:

- in the sectoral context (by types of industries);

- by kinds of the industry-specific equipment (by homogeneous groups of the equipment in the corresponding sector);

- with the differentiation of complex norms for individual types of costs (parts, installation works, supervised installation, commissioning).

Formation of norms should be carried out on the basis of analysis and processing of information from producers/suppliers and collective peer reviews, i.e. through analytical, statistical and expert methods.

Such an approach is proposed to be adopted, among other things, to determine the costs of commissioning highly specialized technological equipment.

\section{Conclusions}

The implementation of the proposed approach will allow to:

1. Eliminate the need to develop a huge number of new estimate norms for the installation and commissioning of modern industry-specific technological equipment the need for which is rare, thus optimizing budget costs for these processes;

2. Determine the estimated cost of the technological equipment by a separate estimated calculation of the established form, taking into account the full set of costs for equipment "in business" (equipment cost, installation of equipment foundations, installation and commissioning works). The form and procedure of the estimate calculation should be established in the updated procedure for determining the estimated cost of construction (MDS 81-35.2004);

3. Form and allocate the estimated cost of technological equipment in the consolidated estimate of the cost of construction (a separate column) in order to further harmonize with financial statements requirements;

4. Distribute competencies and responsibility of state customers: reliability of the estimated cost of construction of capital construction facilities is the responsibility of the Russian Ministry of Construction, estimated cost of technological equipment is the responsibility of the relevant ministries (Ministry of Health, Ministry of Transport, etc.).

The procedure for determining the value of industrial technological equipment is proposed to be fixed in the updated procedure for determining the estimated cost of construction. 


\section{References}

1. O.V. Butkova, R.I. Butkov, On the types of value of machinery, equipment and vehicles in appraisal practice V.1, 2, 30-32 (2017)

2. State itemized estimates for equipment installation (CSIEe-2001) (2001)

3. O.V. Didkovskaya, Economic aspects of management of the building complex in modern conditions: Materials of the 3rd International scientific and practical conference, SSUACE, Samara, 201-208 (2015)

4. O.A. Mamayeva, M.V. Ilyina, Science Review 9, 308-311 (2015)

5. Guidance documents in construction 81-37.2004. Instructions on the application of Federal unit rates for equipment installation (FURe-2001) (2004)

6. Price Indices in Construction, Inter-regional information and analytical bulletin 91, April (2015)

7. V.M. Sidorov, Economy. Innovation. Quality control 3(16), 22-23 (2016)

8. Directory of the appraiser of machines and equipment. Correction coefficients and characteristics of the machinery and equipment market (Ed. by Leyfer L.A., Nizhny Novgorod, 2015) 